\title{
Overcoming fragmentation and waste in health care systems in Africa: Collaboration of health care professionals with pastoral caregivers
}

\begin{abstract}
Authors:
Emem Agbiji ${ }^{1}$

Christina Landman ${ }^{1}$

Affiliations:

${ }^{1}$ Research Institute for

Theology and Religion, University of South Africa,

South Africa

Note:

Emem Agbiji is a postdoctoral research fellow at the University of South Africa. This article was initially a paper delivered at the Annual conference of the Society for Practical Theology on 23 January 2014 at the University of Pretoria. The article addresses the theme of the conference: Practical theology and human waste in Africa.
\end{abstract}

This article is published in the section Practical Theology of the Society for Practical Theology in South Africa.

Correspondence to: Emem Agbiji

Email:

treasureofpeace@yahoo.com

Postal address:

PO Box 329, UNISA 0003 ,

South Africa

\section{Dates}

Received: 07 Mar. 2014 Accepted: 30 Jun. 2014 Published: 07 Nov. 2014

How to cite this article: Agbiji, E. \& Landman, C., 2014, 'Overcoming fragmentation and waste in health care systems in Africa: Collaboration of health care professionals with pastoral caregivers', HTS Teologiese Studies/Theological Studies 70(2), Art. \#2654, 11 pages. http://dx.doi.org/10.4102/ hts.v70i2.2654

\section{Read online:}

This article explores the possibility and limits of collaboration between medical professionals and pastoral caregivers with a view to overcoming fragmentation and waste in the African hospital care sector. It argues that the quality of health and health care in many African countries is poor. Therefore, a purposeful reform of health care delivery systems in Africa is necessary. Building on the World Health Organization's statement that the medical model that focuses on medicine and surgery and ignores the factors of belief and faith in healing is no longer satisfactory, it further argues that the medical model (including the bio-psychosocial model) is not sufficient for holistic hospital care; it therefore needs to accommodate complementary approaches (such as pastoral care) and include these as collaborative treatments. The connection of collaboration with quality, value, relationships and the ending of life implies that collaboration is an ethical process of reflection - which could have a legal implication.

\section{Introduction}

It is generally established that the quality of health and health care in Africa, as well as globally, is in a crisis created by a growing disease burden (Chopra et al. 2009:1029; National strategic health development plan [NSHDP] 2010-2015 of Nigeria [Nigerian Federal Ministry of Health 2010]; World Health Organization [WHO] 2000:23). The complexity of the health crisis manifests in numerous forms of disease, and defies easy response. It is therefore generally accepted to be more than a medical problem and cannot be addressed exclusively as such. As a result, health systems researchers in Africa have advocated a paradigm shift in response to the crisis; this would involve not only 'a new and reflective thinking' (Ceaser \& Theron 2008:165) but also a broad-based and comprehensive approach to the matter. Most significant is the WHOs statement (1998:7) that a medical model that focuses on medicine and surgery but ignores the factors of belief and faith in healing is no longer satisfactory. The realisation that the medical model needs to accommodate complementary and alternative approaches to holistic health care (Doran 2005:39; Ellis \& Hartley 2008:119-121) has opened a space for various healing approaches within the African context, such as the bio-psychosocial approach, the complementary and alternative medicine (CAM) approach, traditional African healing, faith healing, psychology, social work, et cetera. However, the different health care approaches by different health care practitioners have resulted in fragmented health care systems. Health care players (Kreindler et al. 2012:348; NSHDP 2010-2015 [Nigerian Federal Ministry of Health 2010]) have observed that global health care is highly fragmented and that linkages between different levels are weak. Consequently, many countries in Africa are undertaking health care reforms and developing policies to improve health care systems. However, Kreindler et al. (2012:348) contend that the success of health care reforms, policies and practices is dependent on the ability of the designers of health care delivery systems to replace fragmentation and waste with coordination and cost-effectiveness across disciplines. Their claim is substantiated by the National policy on public and private partnership for health in Nigeria (NPPPPHN) (Nigerian Federal Ministry of Health 2005b) which states that:

[O]ne of the key challenges of policy makers is how to form effective partnerships among different players in such a way that health care can be served sufficiently, effectively and equitably.

However, most health care policies in Africa (Nigeria included) have barely articulated the role of belief and values such as religion and spirituality, and there is no draft policy regarding the provision of pastoral care in health care institutions. Most government policies focus on structure, equipment and biomedical science; these policies are good in themselves, but are hardly adequate in providing holistic care for patients and their families in Africa, and they ignore the pastoral component (cf. e.g. National health development plan 2030 [National Planning Commission of South Africa 2011] and the National strategic health development plan (NSHDP)

Copyright: (C 2014. The Authors. Licensee: AOSIS OpenJournals. This work is licensed under the Creative Commons Attribution License. 
2010-2015 of Nigeria [Nigerian Federal Ministry of Health 2010]). It is our considered opinion that such neglect of the pastoral component (that includes religion and spirituality) which is intrinsic to the African patient reality (Dukor 2010:164-214; Mbiti 1999:3) constitutes a waste of human resources for pastoral care and represents lost opportunities for spiritual healing in the hospital environment. The present article contends that this waste of human and spiritual resources for caring and healing could be redeemed through the use of pastoral caregivers (PCGs).

It bears noting that a PCG in the hospital setting and other public institutions is generically referred to as a chaplain. However, the term PCG is used here for the sake of consistency because it reduces the chances of misunderstanding that may be misleading in the African context, as many Africans associate chaplains with ordained pastors who minister to members of their faith groups.

Waste assumes various forms and is variously defined, depending on the field and focus of research. However, a broad understanding of waste carries the idea of harmful substances or objects or services that are threats to human health, to communities and to the environment (Bowman, West \& Van Wart 2013; Lee \& Nash 2009). In this article, waste denotes ideas of disuse, poor quality, loss, neglect, weakness, carelessness, abuse and misapplication of services and human resources. Waste impedes effective performance and strategies, and hinders the optimum use of human resources that could enhance productivity and promote the growth of persons and institutions (Daly 2012:118). By 'human resources', we mean people who make up the workforce (Fallon \& McConnell 2014:7), but the term also refers to the knowledge, assets and skills that a professional brings to an organisation (Wikipedia n.d.). Consequently, human resources for health are defined in this article as the services supplied by professionals engaged in the provision of care whose foremost intent is to enhance health. Given this background, the present article explores the possibilities and limits of collaboration between medical professionals and PCGs in Nigerian hospitals in particular, and in African hospitals in general. The point of departure of this paper is the new interest exhibited by government policies such as the NPPPPHN (Nigerian Federal Ministry of Health 2005b) which calls for the incorporation of CAM approaches to health care.

On the other hand, collaboration in health care institutions may raise some theological, moral and ethical issues that demand reflection as a necessary step towards authentic theological praxis. In this regard, this article adopts a postfoundationalist paradigm of practical theology, within which Osmer's (2008:147-152) normative task of good practice and ethical reflection is employed as the hermeneutical lens for the collaborative engagement. The post-foundationalist paradigm relates theology to science and holds that academic fields have overlapping goals and interpretive processes for arriving at conclusions or judgements that exist at the intersection between disciplines, paradigms and practices
(Van Huyssteen 1999). These processes involve presenting good reasons for one's choices, beliefs, actions, etc. as these have shared resources of rationality and intelligibility. Such a framework allows this article to have a cross-disciplinary transversal conversation (cf. Osmer 2008:163) with the medical sciences without compromising the identity of pastoral care. Although theology and medical science have different points of reference, and different epistemological foci and experiential resources, the transversal reasoning employed in this paper provides common ground for a collaborative vision (Park 2010). Therefore the interdisciplinary task involved in the post-foundationalist paradigm is in a sense a hermeneutical and holistic approach. The holistic vision which serves as a common ground for the PCG and the medical professional is based on a theological understanding of personhood and the African understanding of personhood (Agbiji 2013:61-67; Bujo 2001:115; Metuh 1999:115-117). The attention to quality of care in health care policies and the concern to seek to review such policies so as to include PCGs in the hospital team also implies the need to legitimise pastoral care as a professional discipline.

\section{Pastoral care as a professional discipline}

Let us begin by stating that both spiritual and religious care are dimensions of pastoral care (Cobb 2005:43). We refer generally to spiritual care as entailing the 'meaning-making' of patients, while religious care is that aspect of care that deals with the rituals and practices, narratives and doctrines, of the faith traditions of patients (Orton 2008; VandeCreek 2010; VandeCreek \& Burton 2001). However, spirituality is linked with religion in the hospital care setting in Africa, and these terms are therefore used interchangeably in this article because both concepts are contextual in nature (Hirsto \& Tirri 2009:90). For most African patients, religion is a way of life. There is no separation between spirituality and religion (Conte 2011:61).

All the same, pastoral care has always been embedded in the Christian understanding, and is known as the care of souls (Anderson 2003:14; Johnson 2001:40-41). Pastoral care as soul care is the core of pastoral care ministry, which is directed towards the care of the whole person (Gerkin 1997:21-22). This implies that pastoral care expresses what it is to be human. Humans are assumed to be complex and constantly in a state of change and transformation. Pastoral care, by virtue of being associated with the concerns of people, attempts to respond to their needs; it has a complex character, expressed in its varied definitions and practices (Hawkes 1991; Ramsey 2004). Accordingly, the notion that pastoral care involves a response to human experience is central to the tradition of care. Care does not exclude the search for cure (Anderson 2003:14). This vision of pastoral care implies being present to those in sickness, injury and suffering, as well as taking the risk of addressing forms of evil and attempting the restoration of justice. Caring is healing (Koopman 2006). 
Koopman (2006:38-40) contends that caring as healing might help the suffering person to experience health as the strength needed for human life, the strength to live a life of humanness, dignity, worth, value, wholeness and shalom [peace]. Caring as healing does not necessarily mean curing an ailment but rather refers to a restoration of the whole that connects with the spiritual dimension. The connection of care and healing is an implicit identification with both the physical or human dimension and the spiritual dimension involved in pastoral care. To care implies both the 'being' and the 'doing' components; it stems from the understanding that care is a service to God and humanity. In essence, pastoral care expresses a wholesome personality and engagement with life that includes the spiritual, ethical and social dimensions (Igonoza 1994:128; Louw 2008:15-17). For this reason, Cobb (2005:43) has conceptualised pastoral care as a 'practical embodiment of beliefs in humanity with a theological framework that is critically sensitive to context and disciplined in his [sic] response'.

The above understanding of pastoral care establishes it as a critical constructive reflection of the faith communities, undertaken consistently in the context of the caregivers' praxis. This praxis draws on the caregivers' interpretations of the normative sources of scripture, tradition and experience in response to changes they face and leads to ongoing modifications and transformations of their practices in order to be more adequately responsive to God's calling. It is also a theological discipline rooted in the praxis of God and the participation of the community of faith in God's plan through reflection in theology, theory and the practice of care. It further reveals that pastoral care strives for competent, efficient and credible practice by developing a framework for education, training, conduct and performance and for the regulation of a practice that is at the core of all professional discipline (Ellis \& Hartley 2008:152; Smeet et al. 2011; Swinton 2003). Such professional identity reconstruction and review of approaches suggests an open theological method that can be incorporated into hospital care at various levels for holistic and improved quality hospital care. However, to what extent can the PCG be considered as a health and health care resource?

\section{Establishing the PCG as a health care resource}

According to the NPPPPHN (Federal Ministry of Health 2005b):

... alternative health care providers, whose practices are of proven value, shall be encouraged and supported as frontline of health care provision for many people. Such providers will be brought under regulations to ensure adherence to rules and health care guidelines.

This policy statement raises two questions: Who are the PCGs? What is alternative and complementary health care?

PCGs in the hospital context are pastoral care experts (pastors, rabbis, imams, lay persons) who deliver spiritual and religious care services to patients and staff in medical contexts, irrespective of their religious affiliations. Their identities vary according to training and their theoretical orientation within particular cultural and social contexts, and they exhibit certain qualities that allow them to perform their roles appropriately (Agbiji 2013:205-225). Hence, different categories of PCG are or may be operational in the hospital context: the pastoral visitor, the volunteer and the professional PCG are all recognised in this article, but particularly the professional PCG. Professional PCGs are theologically and clinically trained care professionals whose work involves understanding the spirituality of patients and providing pastoral care appropriate to careseekers' expectations and needs. Hence, professional PCGs have a basic knowledge of relevant aspects of clinical sciences: they will be familiar with common medical terminology, with major disease processes, with diagnostic investigations and with common types of therapy and patient management (Cobb 2005:26). This definition leads to a further question: can the PCGs' resources be considered as examples of CAM practices that could be valuable to the health care profession?

The National Centre of Complementary and Alternative Medicine (NCCAM) (2011) defines CAM as a 'group of diverse medical and health care systems, practices and products that are not generally considered as part of conventional medicine'. It explains that CAM is usually used to reduce the side-effects of treatment, such as pain and fatigue. NCCAM has classified CAM in terms of five broad categories that cannot be elaborated on here. However, significant in this classification is the inclusion of prayer, meditation and healing touch as forms of CAM. Koopsen and Young (2009:xiv-xx) therefore argue that CAM includes nutrition, spirituality and stress management as components of a holistic and integrative approach to health care. Accordingly, Stuber and Horn (2012:195) conclude that CAM entails 'deeply spiritual approaches to health and the integration of the body, mind and spirit'. Koopsen and Young (2009) further explain that 'integrative medicine' involves:
... the concept of communication among all health providers who share the responsibility in coordinating the best possible treatment plan for a client, including the client's choices of care providers' expertise in understanding and managing the complexities of conventional-complementing treatment interactions. (p. $x x)$

The overall goal of integrative medicine is the healing of patients and the overall improvement of their health by charging them with responsibility for their situation while the caregivers or healers maintain a supportive role. In consequence, integrative medicine is holistic medicine and is concerned with healing as wholeness rather than with a specific disease (Koopsen \& Young 2009:xx). Wholeness is reflected not only in a person's physical well-being or in the actual wellness of the body, but also in caring relationships and connectedness with oneself, God, others and the environment. Subsequently, health researchers 
such as Eaton and Agomoh (2008:552-558), Afolanyan and Okpemuza (2011:31-40) and Antai (2009:57-76) have located the success of health care performance in the patient's belief system in general and in religion in particular. They argue that belief systems are important components of the health and illness behaviour of patients; they influence the choices that patients make when they fall ill and should be considered in the care and healing process. Significantly, Landman (2013:248), writing from a theological perspective, conducted empirical research among youths in a South African township to ascertain the role of religion as a health asset as well as an influence on the youths' expectations of their religious institutions (churches). It emerged from her studies that, among other things, religion served as a coping skill for the debilitating conditions that adversely affect their health. In various ways, religion fostered hope and healing and therefore reduced the emotional waste of frustration in the midst of joblessness, poverty and ill-health. Her research established religion as an important health asset for poor communities in South Africa.

Furthermore, studies across countries and cultures also indicate that many people rely on spiritual and religious resources during hospitalisation to help them cope with their predicament (Flannelly, Handzo \& Weaver 2003:760-768; Ibrahim \& Odusanya 2009). Similarly, a number of empirical studies carried out to determine the extent of patients' reliance on hospital PCGs and to assess their evaluation of hospital PCGs have also established the high value that patients place on hospital PCGs (Chattopadhyay 2007:262-267; Piderman et al. 2010:1002-1010). Koopsen and Young (2009) argue that:

Chaplains [PCGs] are also a tremendous staff resource since they can assist staff members in coping with their own grief and provide education in the areas of ethics, spirituality, and coping strategies. (p. 53)

Empirical research also confirms the value of PCGs to the medical staff (Flannelly, Weaver \& Handzo 2003:760-768; Flannelly et al. 2005:19-27).

These research studies connect healing and hope, ill-health and health care, and health and wholeness to wholesome relationships, belief systems and religion and underscore the vital point that PCGs are an important health care resource. They establish PCGs not only as alternative but as complementary health care providers whose resources are invaluable to the health care system. According to Koopsen and Young (2009:50), PCGs are 'a valuable spiritual resource in health care organisations'. This is evident in the incorporation of pastoral care in health care policies and reforms in the United Kingdom (UK) and the United States of America (USA) (Orton 2008). Cobb (2005:26) in fact considers PCGs as allied health care professionals. The complex reality of illness therefore necessitates the collaboration of medical care professionals with PCGs for holistic healing. The question then arises: is there a possibility for PCGs to collaborate with health care professionals?

\section{Collaboration with PCGs in hospital care}

Theologically, there is increasing evidence that supports the biblical statement that 'a cord of three strands cannot be easily broken' (Ec 4:12). This wisdom is gaining ever more recognition and acceptance in our world today. Howard Clinebell's words of wisdom many years ago are increasingly relevant to contemporary African hospital care when he argues that:

... the need, opportunity, and resources for clergy-doctor collaboration are greater today than at a previous period of history. In a society that fragments persons and relationships, it is imperative that healers get together. Otherwise, they will continue to contribute to the splintering of contemporary man. It is particularly important that healers of the body and clergymen, the healers of relationships (with self, other, and God), learn to work together more effectively as they deal with the same individuals and the same families. (Clinebell, cited in Balch 1991:53)

Significantly, the NPPPPHN (Nigerian Federal Ministry of Health 2005) states that collaboration can contribute to creating a positive and enabling space to provide for the synergy of partners for improved services; this would not have been possible had they acted individually. It is worth noting that although we acknowledge the good efforts of the governments and other health care decision-makers, such collaborative efforts cannot and should not be limited to collaboration amongst health care professionals, and must of necessity be extended to PCGs.

Encouragingly, collaboration is one of the seven strategic objectives in the National Health Sector Reforms (HSR) programme of the Nigerian Federal Ministry of Health, (NPPPHN 2005b). The goal of these reforms is to safeguard health, to do good and no harm to the patient - or to reduce suffering, to use a pastoral term. In this regard, the Geneva Convention's Code of Medical Ethics (quoted in Campbell, Gillet \& Jones 2005) states:

The health of my patient will be my first consideration. Such health embodies a holistic vision of patient well-being, which drives all to seek the summum bonum [highest good] of patients through interdisciplinary collaboration. (p. 31)

Campbell et al. (2005) further remark that:

\begin{abstract}
... the most dangerous practitioner is the 'loner' who attempts to work in isolation from colleagues in the field, and without reference to those who have different expertise either within the medical disciplines or other professional field. In order to work in the best interest of patients every practitioner must learn to share the decision-making process with others, to consider alternative diagnoses and treatment, and to find correction or support when the decisions are specially difficult and uncertain. (p. 31)
\end{abstract}

Collaboration is therefore a moral and ethical responsibility that all health care and pastoral care professionals have towards the sick and suffering in hospital, despite the apparent challenges. This view implies that medical 
professionals and PCGs should be guided by an ethic of altruism (serving the interests of others) rather than egoism (serving one's personal interests). But how is collaboration to be understood?

Overall, collaboration is conceptualised as an interpersonal process through which members of different disciplines contribute to a common goal that cannot be reached when individual professionals act alone (Bronstein 2003:299). Collaboration, however, comprises several sub-concepts that include communication, coordination, shared decisionmaking and teamwork. Collaboration in essence is aimed at achieving teamwork. Another term related to collaboration is consultation. Dougherty (2009) defines consultation as a:

... process in which a human service professional assists a consultee with a work-related (caretaking-related) problem with a client system with the goal of helping both consultee and client system in some specific way. (p. 11)

The primary reason for consultation, according to Dougherty (2009:11), is that the expertise of the consultant is considered valuable for solving the problem. Although consultation is similar to collaboration, the difference between them is that consultation 'is a stand-alone service' (Dougherty 2009:11) between the consultant and the consultee, while collaboration involves the combined efforts of two or more experts on a particular issue. The major weakness of consultation vis-àvis collaboration is that it is temporal. The relationship lasts only as long as the problem persists. Collaboration could be a one-on-one experience as consultation, or a group process as teamwork. Consequently, consultation, teamwork and collaboration are useful means of providing quality health care to patients. It should be noted at this point that most hospitals in Africa sometimes partner with religious leaders on a consultative basis, but collaboration with the PCG (in terms of teamwork) is almost non-existent. Nevertheless, care for the sick and suffering involves relationships of trust, which present both possibilities and limitations. According to Doran (2005:40), collaboration in the hospital involves a relationship of trust, respect and the joint contribution of knowledge, skills and values to accomplish the goal of quality patient care. Sometimes such a caring relationship involves co-opting others into the relationship. However, there is a need to examine the basis for collaboration between PCGs and medical professionals.

\section{Basis of collaboration}

The role of religion and the increasing recognition of this role by health care authorities has become evident (NPPPPHN [Nigerian Federal Ministry of Health 2005b]; WHO 1998). Also, the mind-body-spirit interconnectedness (WittenbergLyles et al. 2008) as well as the collaboration history of church (religion) and hospital (Ecoma 1996:177-178) provide a basis for collaboration. It should be stressed here that an African holistic concept of religion and life makes no distinction between the sacred and the secular. In this light, the contemporary practice of medical caregiving needs to reflect the African spirituality and religiosity which takes into consideration all dimensions of human and cosmic life. Landman's $(2009,2013)$ outstanding studies of township spiritualities and identities within the South African environment again highlight the impact of religion on the identities and on the general life of many South Africans, and illustrate the ever-growing need for pastoral counselling in that context. Collaboration with PCGs further acknowledges the religious or spiritual values that patients and families place on their health needs; these in turn influence their choice of hospital and healing intervention (Koenig, King \& Carson 2012). The limitations of medicine also make clear the basis of collaboration (Hill \& Smith 2010:175; Read 2006:6). The Nigerian Code of Medical Ethics recognises the fact that medical professionals have limits in the provision of care, and it calls medical professionals to admit this fact. Limitations need to be acknowledged and addressed rather than ignored. Limitations that are ignored impede the optimum use of resources and lead to the neglect of other resources that could have been utilised for holistic and efficient health care. Limitations, then, call for combining the resources of all relevant professionals to achieve holistic and quality care for the care-seekers. Hence it behoves health care professionals to collaborate with PCGs. However, for health care professionals and PCGs to collaborate effectively and avoid fragmentation and minimise the waste of resources, they need to understand the nature of the collaborative relationship. Health care organisations waste resources when human resources are not harnessed efficiently (Fallon \& McConnell 2014:429).

\section{Nature of the collaboration}

The nature of the collaboration should be symmetrical. De Lange (2011:2-5) defines a symmetrical relationship as one in which both partners in the relationship are equal in relation to achieving the goal of their relationship, and they should function as colleagues. This means that such relationships should be equal in interest as partners, in dignity as human beings, and in rights and obligations as caring partners. In the light of De Lange's insight and Bronstein's (2003) view of interdisciplinary collaboration, this study proposes four components as definitive for the nature of collaboration between PCGs and medical professionals.

\section{Relationship of equality/complementarity}

According to Campbell et al. (2005:320), health care is a growing body of expertise and entails shared respectful and collegial relations between health care workers (Campbell et al. 2005:13). They suggest that the ideal relationship amongst caring professionals should be a mutual one for the purpose of support and honest criticism. Given this background, the collaborative relationship between PCGs and other health care professionals should be perceived as a symmetrical relationship of equality in terms of the goals, functions, obligations and respect for the dignity of one another in the caring relationship. Mutual respect between medical personnel and PCGs could enhance the functionality of their relationship within the medical team in the hospital context. 


\section{Relationship of mutual respect}

Mutual respect is an important factor for successful collaboration (Balch 1991:49; Chappelle 2006:213; Eyer 1991:19). Mutual respect refers to mutual understanding and the appreciation of each other's unique competencies, to the willingness and opportunity to communicate and to more frequent opportunities to work together. For this reason, PCGs seek to collaborate with medical personnel not to compete for relevance or supremacy, but as partners towards achieving the common goal of alleviating suffering where possible and helping patients to generate meaning in their situation.

\section{Collaboration with shared goals and benefits}

Shared benefit is engendered by what Bronstein (2003:301) calls 'the collective ownership of goals', which involves a shared responsibility for the entire process of defining, developing and attaining goals. The collective ownership of goals could in turn lead to newly created professional activities which are collaborative acts that can achieve more than could be achieved by that same professional working independently (Bronstein 2003:300). Collaboration with shared benefits does not allow for a contest of power and authority, where the medical professional may see the PCG as a threat or as not worthy to occupy the same space. Shared benefits also necessitate flexibility of roles which often involves a fruitful compromise, in which case roles are intentionally blurred.

\section{Clarity of roles and identity}

Reese and Sontag (2001:2) note that ignorance on the part of the collaborative partner of the expertise, skills, training values and theory of the other partner strains the collaborative relationship. They view such ignorance as arising from the way in which health care professionals receive their training in isolation from others. Therefore, it is the duty of PCGs and medical personnel to clarify their identities and roles to one another - and not simply assume that collaborative partners and patients understand their tasks. There is a moral and ethical imperative to uphold the human dignity of all in the process of caregiving.

\section{The ethical process in collaboration}

Moodley (2011:3) remarks that 'care is central to morality in the ethics of care'. Accordingly, in a health care setting, care is guided by an ethos or code of ethics that also involves a process of moral reflection which may sometimes have a legal tone. This ethical endeavour may help to clarify professional identities and relationships that enhance the quality of service delivery. Ethical reflection therefore serves to guide human conduct; it also assists persons or a group to conform to the norms of morality to achieve better outcomes, which enhances the dignity of the human being. As Ashley and O'Rourke (1989:15) insist, the principle of human dignity is involved in all ethical decisions, which should satisfy both the innate and cultural needs of the person. A good ethical process thus enhances growth and reduces the waste of human health resources.
Health care and pastoral care professionals are guided by an ethos, albeit from different perspectives and foundations; this ethos guides their professional practice and relationships with others. However, regarding the professional relationship with other professions or practitioners, a collaborative relationship may present a moral dilemma and blur their understanding of what ought to be. Collaboration may sometimes accentuate the uncertainty and dilemmas faced by health care professionals. However, when there is a common goal, such dilemmas might be easier to deal with and might even be surmounted. Therefore, to achieve success in collaboration through consultation and teamwork in hospital care in Africa, PCGs and health care professionals must be aware of whatever influences the process of collaboration and its possibilities and limits. Therefore confidentiality, referral, informed consent, documentation and biomedical ethical implications are some of the issues through which the possibilities and limits of collaboration may be articulated.

\section{Confidentiality}

Confidentiality is a central concept in the helping professions. It forms the core of medical practice because it is connected to the patient's right to autonomy. Respecting patients' autonomy is one of the four main principles or rights of patients in health care. Respecting the patient's autonomy is demonstrated by respecting the patient's privacy, protecting confidential information and obtaining informed consent. In health care, this will entail 'allowing the patient to make the final decision regarding his or her treatment after providing all the necessary and relevant information' (Moodley 2011:42). This policy suggests that, under normal circumstances, information shared between the patient and the medical professional cannot be transmitted to a third party without the patient's knowledge and express permission. Elger (2009:517) remarks that, within the medical setting, a patient's right to confidentiality extends beyond death and therefore is a cornerstone of medical ethics. This is because a breach of such confidentiality has moral and legal implications for hospital care; it raises the question of trust as the information shared within that relationship is often personal, intimate and may reveal the patient's vulnerability, such as feelings of shame, guilt, helplessness, et cetera.

The obligation to obtain consent from patients and the protection of their confidential information is paramount in the health care setting. The need for confidentiality and informed consent is stipulated clearly by the Nigerian codes of Medical Practice and Pastoral Care and by the literature on counselling. In the Nigerian Medical and Dental Association, confidentiality forms part of the code of conduct for professional practice and the maintenance of human dignity (Code of Medical Ethics in Nigeria 2004:52). Part D of the Code is entitled 'Improper relationship with colleague or patient'; Code No. 44, headed 'Confidentiality', states:

The profession takes very seriously the ethics of professional secrecy whereby any information about the patient that comes to the knowledge of practitioner in the course of the patient doctor- 
relationship constitutes a secret and privileged information which must in no way be divulge by him to a third party. The medical records are strictly for the case and sequence of continuing care of the patient and are not for the consumption of any person who is not a member of the profession. Practitioners are advised to maintain adequate records on their patients so as to be able, if such a need should arise, to prove the adequacy and propriety of the methods, which they had adopted in the management of the cases.

The complex character of confidentiality creates a challenge for health care workers and may sometimes hamper collaboration with others outside the fold. Erde et al. (2006:398) observe that confidentiality and privacy sometimes present a dilemma for hospital delivery of health care. However, the principle of autonomy and confidentiality is not an absolute rule but rather a prima facie rule that must be fulfilled in the absence of another stronger rule (Moodley 2011:42). In other words, there are instances where a breach of confidentiality could be justified; that is, where such a stance may actually impede the quality of health care service provision, especially where innovation is required. Confidential information is often shared among health care team members and is noted in medical records (McCurdy \& Fittchet 2011:61). Medical records pose a particular challenge to confidentiality as third parties can access such information. Although consent is supposed to be obtained from the patient by a third party before such information is accessed, this does not happen in many instances - and for many reasons. The advent of information technology also poses a particular challenge to confidentiality, as a growing volume of medical records and a great deal of health information are now stored on electronic databases. Persons other than health practitioners can easily access information stored on databases. These databases are also vulnerable to hackers, viruses and spyware, which might result in disclosure of this information for selfish ends (Dhai \& Etheredge 2011:29-30).

Dhai and McQuoid-Mason (2011:87) therefore state that when patients choose to share some information with their practitioner, they choose to relinquish their privacy. Consequently, they advise that patients should be made aware of the limits of confidentiality and should make an informed decision and give consent before information is shared (not afterwards). It follows that it would be erroneous to assume that the ethics of confidentiality (as described above) rule out possible collaboration with professionals outside the health care profession. Rules regarding confidentiality and privacy may differ from context to context and according to the nature of relationship and the position of the PCG in the hospital space. For instance, the debate in the United Kingdom on whether a PCG is a member of a team does not arise as they are seen as members of the health care team. Thus, the question of whether sharing information with a PCG is a breach of confidentiality can be clearly answered. However, in the USA (in some health care institutions), the ambiguity of the PCG in the health care team causes some debate (Tovino 2005:59-60). Therefore, at stake in the PCG-medical professional collaboration is the issue of role identity in the hospital context. These problems can be reduced by clarifying the role of PCGs and the extent to which they are to be involved in hospital care.

When PCGs are considered to be valued members of a team, information shared by a physician or nurse or any other health care practitioner with the PCG, which is relevant to the case and is for the sole purpose of providing pastoral care, should invoke appropriate confidentiality and not be regarded as a breach of the code. It is hoped that such collaboration can be developed to the extent that patients indicate interest in and a desire for pastoral care. Such interest can be identified at the admission of each new patient, at which time the function of PCGs and the nature of their services can be clearly explained to the patient. The patient is given the opportunity to consent to pastoral visits as part of the therapeutic intervention, in which case a clear record is maintained of the pastoral intervention given.

\section{Informed consent}

The principle of informed consent is an offshoot of the autonomy principle of a human being who is capable of reason and of making choices based on his or her values and beliefs with the aim of satisfying the desire for self-realisation, self-transformation, self-development and the search for meaning. Informed consent is therefore a core aspect of clinical ethics and bioethics devised in a legal situation to prevent harm to patients. Beauchamp and Childress (2009:105) define informed consent as 'an individual's autonomous authorisation of a medical intervention or of participation in research'. This consent can be verbal, express, tacit or implicit; legally valid authorisation from a patient or family often takes the form of a specified written format before any treatment or research. Such consent is intended to safeguard people's privacy and ensure respect for individual autonomy; it might not only involve giving the patient the chance to make choices, but also involve giving them the option not to make decisions when they do not wish to do so. From a pastoral care perspective, informed consent can be said to be rooted in the concept of the image of God, the imago Dei. God always gives man the freedom to choose after explaining the consequences of each action (Dt 28:1-68). Jesus could also be said to have practised informed consent before embarking on healing his patients. He often asked: What do you want me to do for you? Do you want to be healed? (Jn 5:6).

In this regard, informed consent in the physician-PCGpatient relationship entails both the patient's autonomous consent and the observance of the institutional or legal rules for informed consent. It is believed that, in many hospitals, patients would be briefed by the hospital administration on the modes of working with patients in the hospital on their first visit or on admission to the hospital, as part of good medical practice. Responsible hospital care requires that patients take part in determining what should or should not be done to or for them (cf. WHO Key Components of a Well- 
functioning System 2010). Underlying this argument is the assumption that no one understands patients better than do the patients themselves; they are the experts on their own lives. This means that they 'have many skills, competences, beliefs, values, commitments and abilities that will assist them to reduce the influence of problems' (Morgan 2000:2) if motivated appropriately. This view enables patients to exercise their autonomy in an informed and responsible way as human beings and not simply as objects or case studies. Such information is intended to allow patients the opportunity to understand how the different medical professionals operate in attempting to obtain the best possible practice and outcome in terms of patient care and to ensure continuity. As Beauchamp and Childress (2009:106-107) explain, patients, by giving informed consent, delegate their right of autonomy to medical staff who act on their behalf. This enables collaboration of medical professionals with PCGs to provide pastoral care to patients who have given general consent to the medical administrators to provide them with holistic medical care (this consent extends to other professionals involved in the case). However, where a physician or nurse faces a dilemma or is unsure as to the extent of the collaboration, informed consent can still be received from a patient as it concerns specific procedures that may arise and that might not have been discussed with the patient. The physician or nurse could also liaise with peers and other colleagues to determine the best approach - rather than simply ignore this vital issue out of fear or by making assumptions. In essence, each case should be taken on its own merits. As a matter of fact, it is expected that consent be sought from patients before they are referred to PCGs for consultation.

\section{Referrals}

The referral process is a means of bringing every available resource to bear on a particular situation. There is a growing awareness that many professionals are less able to meet the needs of patients on their own without collaboration (Bronstein 2003:299). As part of a collaborative approach, it is necessary to recognise the limits of one's competence and the extent to which one can offer significant help to patients. The NSHDP 2010-2015 (Nigerian Federal Ministry of Health 2010:44) has highlighted as one of its goals the strengthening of the referral system and mapping network linkages for a two-way referral system. In this regard, the Code of Medical Ethics in Nigeria (2004) states:

$$
\begin{aligned}
& \text { It is desirable and indeed a requirement of ethics that every } \\
& \text { practitioner in dealing with patients must recognise his own } \\
& \text { limitations in skills and facilities, and thus be able and willing } \\
& \text { at all times to refer such circumstances to better skilled or better } \\
& \text { equipped colleagues or hospitals. It is professional misconduct } \\
& \text { for a practitioner to cause detriment to a patient by failing } \\
& \text { to refer to others a case he [sic] cannot handle effectively. } \\
& \text { (p. } 53 \text { \$11a) }
\end{aligned}
$$

In the light of the above statement, an appropriate referral should take into account the timing of the referral, the process of the referral, and the available resources for the referral. Collaborative practices in terms of referrals are necessary because of the requirement for accountability and for documentation of complex diagnoses and treatment plans. Such complexities often fall short of what individual training can provide. In this regard, referral forms part of the professional ethos and ethics of health care. The pattern of professionals clinging to an exclusive relationship because of a feeling of omnipotence or possessiveness, or out of fear that their inadequacies might be exposed, goes against the ethical imperative to act for the benefit of the patient. Carey and Cohen (2009:353) observe that there has been an increasing debate among physicians regarding the inclusion of pastoral care as part of holistic care; however, instead of undertaking this themselves, they should collaborate with PCGs to realise this goal.

The implication for the African hospital system, which may seek to commit to holistic health care, is that the hospital system should regard pastoral care as an authentic component of the patient's well-being and a necessary factor in the patient's healing process. This approach is in line with the holistic view of life of Africans and with the WHOs Quality of Life WHOQOL index, which includes spiritual and religious beliefs as one of its domains of assessment (WHO 1998:5). By using a simple spiritual inventory, the medical professional can identify the needs of patients and refer them to PCGs for appropriate intervention instead of ignoring them or applying a medical solution to a pastoral need. Basic forms of spiritual care can be, and should be, provided by all professionals within the hospital context, for only then can medical professionals assess and recognise a particular patient's need for more sensitive and competent pastoral intervention. However, collaboration also necessitates maintaining professional boundaries as an ethical norm.

\section{Maintaining ethical boundaries}

The maintenance of ethical boundaries requires that professionals in the hospital context, such as doctors, nurses and pastoral caregivers, should have a deeper understanding of what professionalism entails. Such understanding goes beyond technical expertise and remuneration, and involves clear and appropriate loci of responsibility (Hunter 1995:28). It also means that keeping boundaries should necessarily involve clarity regarding roles, skills and expertise, as well as acknowledgement of competencies. Although there may be an element of role blurring involved in boundary shifting, role blurring should not be taken as the norm. Therefore, maintaining professional boundaries will enhance complementarity and mutual respect regarding ethical responsibilities. In essence, collaboration emphasises the importance of professional accountability in caregiving. It is worth noting that being accountable also entails documenting the caregiving process.

\section{Documentation}

Cobb (2005) rightly remarks that documentation of patient care is established good practice for health care 
professionals, with ethical and legal obligations as defined by the Data Protection Act. In this sense, documentation serves a risk-management function and brings to the fore an important ethical issue in health care that may also have legal implications when linked with the issues of confidentiality, informed consent and referrals.

The importance of documentation in health care is further emphasised in the Code of Medical Ethics in Nigeria (2004):

A member of the medical profession who hands over [or refers] his patients to another must take every endeavour to ensure that the case is handed over with appropriate details of the case history in reasonable time for his colleague to acquire a grasp of the case. (p. 50, part D, 42D)

\section{Cobb (2005) argues that:}

When a patient is referred to a chaplain [PCG], either as a referral by a health professional or as a self-referral by the patient, a minimum set of information is required by the chaplain that needs recording. (p. 113)

Documentation of the medical records of patients may also reveal some of the biomedical ethical decisions that health care professionals are confronted with.

\section{Biomedical ethical implication of collaboration}

The core concern of biomedical ethics is the question of the nature and meaning of life. New methods of research in biochemical, pharmaceutical and medical care have resulted in dramatic developments in health care that have complicated the issues of life and death - the two basic elements of our nature (Louw 2008). In consequence, 'clusters of theological and ethical issues arise, relating to God's sovereignty, man's value and stewardship of creation's resources' (Louw 2008:285). The ethical dilemma involved in caring procedures must necessarily involve a theological perspective in attempting to address such questions. The very complexity of this biomedical issue suggests that a definitive answer from a singular perspective is impossible. Therefore, it may be appropriate to claim that ethical decision-making is not about the final decision itself, but about the steps taken to reach the decision; in essence, it is about the quality of the process. This may also imply the 'who, what, why and where' of the process. When the issue of meaning is introduced, it takes the discussion beyond mere medical ethics and invites other perspectives, such as pastoral ethics, into the discussion. Therefore, biomedical ethics could be viewed as having a connection with ethics and modern medical technology as it affects the control of human life. In this regard, the Draft health promotion policy (DHPP) (Nigerian Federal Ministry of Health 2005a:12), NSHDP 2010-2015 (Nigerian Federal Ministry of Health 2010) and NPPPPHN (Nigerian Federal Ministry of Health 2005b) policies of Nigeria, for instance, may represent steps in the right direction. Specifically, the DHPP (Nigerian Federal Ministry of Health 2005a:12) states as one of its underlying principles and values the importance of partnership and collaboration amongst professional groups. The collaboration of health professionals with PCGs points towards an ethical responsibility that could 'empower individuals and communities to make informed decisions about their health' (DHPP [Federal Ministry of Health 2005a:12]); the NSHDP 2010-2015 (Federal Ministry of Health 2010:45) aims to contribute to the quality of care offered by health facilities and to an increase in their use by Nigerian citizens.

\section{Conclusion}

The concept and practice of health care as guided by the biomedical model (including the bio-psychosocial model) is not only limited in terms of the provision of health care to the majority of Africans, but is also lacking in the fundamental spiritual and religious dimensions of care. These shortcomings therefore constitutes a waste of significant human resources in the provision of health care. The negative effects of waste have become such a menace for people, communities and organisations that governments are embarking on a 'war on waste' via health care policy reforms. The war on the waste of human health resources cannot succeed if attention is not given to pastoral care, because religious beliefs and values are an integral part of Africans' spirituality and also control their illness-health behaviour. Spirituality is therefore relevant to the way in which they daily negotiate their significance, identity and purpose. While it may be true that health care professionals with exposure to a theological discipline could better bridge the gap between patient, family and community, the enormous burden of disease, time constraints and the shortage of medical professionals present a challenge to a meaningful, sustainable and holistic approach to health care in many African countries. Version 4 of the Diagnostic Statistical Manual for Mental Disorders (DSM IV), for instance, lists 366 mental disorders, enough to provide a different psychopathology for each day of the year (including leap years). It is argued that PCGs are the most viable link between health care professionals and the community, and are therefore a valuable health resource. Consequently, government policies in Africa must of necessity give prime place to pastoral care in their health care reforms, as do health care policies and reforms in USA and UK. They should also become important collaborative partners with health care professionals. However, to achieve success in collaboration through consultation and a team approach in Nigeria/Africa, PCGs and health care professionals must be aware of the various factors that influence the collaborative processes, and the way these can facilitate or impede success.

Collaboration involves ethical, moral and spiritual concerns regarding health care. It highlights the fact that to provide high-quality care collaboratively, health care professionals and PCGs must understand and respect their clients' needs, attitudes and concerns. This in turn will lead to improved client satisfaction, dignity and worth. Health care involves a process of moral reflection as it affects the quality, value and dignity of human life and relationships. 
Ethical practice also entails maintaining professional boundaries as well as adopting appropriate ethical discernment with regard to the biomedical process of caregiving. A collaborative approach through teamwork is a moral and ethical responsibility that health care and pastoral care professionals owe their patients, and this could lead to the harmonisation of inputs into hospital care, and higher ethical standards; it could also minimise fragmentation and reduce the waste of human resources in today's modern health care institutions.

\section{Acknowledgements}

This article is based on work that was supported by the National Research Foundation (NRF) of South Africa under grant no. 88489. Any opinions, findings, conclusions or recommendations expressed in this article are those of the authors, and the NRF therefore does not accept any liability in regard thereto.

\section{Competing interests}

The authors declare that they have no financial or personal relationship(s) that may have inappropriately influenced them in writing this article.

\section{Authors' contributions}

E.A. (University of South Africa) was responsible for the conceptualisation of the title, theme and structure of the article as well as the drafting of the article. C.L. (University of South Africa) was responsible for revising and editing the article.

\section{References}

Afolanyan, J.A. \& Okpemuza, M., 2011, 'Socio-cultural factors affecting mental health service delivery in neuropsychiatric hospital', Continental Journal of Nursing Science 3(1), 31-40.

Agbiji, E., 2013, 'Pastoral caregivers in the Nigerian hospital context: A pastoral theological approach', PhD dissertation, Stellenbosch University.

Anderson, R.S., 2003, Spiritual caregiving as a secular sacrament: A practical theology for professional caregivers, Jessica Kingsley, London.

Antai, D., 2009, 'Faith and childhood survival: The role of religion in childhood immunization in Nigeria', Journal of Biosocial Science 49(1), 57-76. http://dx.doi. org/10.1017/S0021932008002861

Ashley, B.M. \& O'Rourke, K.D., 1989, Healthcare ethics: A theological analysis, 3rd edn., The Catholic Health Association of the United States, St Louis.

Balch, F., 1991, 'Strengthening chaplain-physician relationships in long-term care settings', in L. VandeCreek \& L. Burton (eds.), The chaplain-physician relationship, pp. 47-57, The Haworth Press, New York.

Beauchamp, T.L. \& Childress, J.F., 2009, Principles of biomedical ethics, 6th edn. Oxford University Press, New York.

Bowman, J.S., West, J.P. \& Van Wart, M.R., 2013, Human resource management in public service: Paradoxes, processes and problems, SAGE Publications, Thousand Oaks.

Bronstein, L.R., 2003, 'A model for interdisciplinary collaboration', Social Work 48(3), 297-306. http://dx.doi.org/10.1093/sw/48.3.297

Bujo, B., 2001, Foundations of an African ethic: Beyond the universal claims of Western morality, Crossroad Publishing, New York.

Campbell, A., Gillet, G. \& Jones, G., 2005, Medical ethics, 4th edn., Oxford University Press, South Melbourne.

Carey, L.B. \& Cohen, J., 2009, 'Chaplain-physician consultancy: When chaplains and doctors meet in the clinical context', Journal of Religion and Health 48, 353-376. http://dx.doi.org/10.1007/s10943-008-9206-x

Ceasar, N. \& Theron, F., 2008, 'Commmunity health: The community healthworker as change agent', in F. Theron (ed.), The Development change agent: A micro-level approach to development, pp. 147-172, Van Schaik, Pretoria.
Chappelle, W., 2006, An airforce psychologist's collaboration with clergy: Lessons learned on the battlefield of Iraq', Journal of Psychology and Christianity 25(3), 205-215.

Chattopadhyay, S., 2007, 'Religion, spirituality, health and medicine: Why should Indian physicians care?', Journal of Postgrad Medicine 53(1), 262-267. http:// dx.doi.org/10.4103/0022-3859.33967

Chopra M., Lawn J.E., Sanders D., Barron P., Abdool Karim S.S., Bradshaw, D. et al., 2009, 'Health in South Africa 6: Achieving the health millennium development goals in South Africa: Challenges and priorities', Lancet Series 374, 1023-1031. http://dx.doi.org/10.1016/S0140-6736(09)61122-3

Cobb, M., 2005, The hospital chaplains handbook: A guide for good practice, Canterbury Press, Norwich.

Code of Medical Ethics in Nigeria: Rules of professional conduct for medical and dental practitioners, 2004, viewed 27 October 2011, from http://www.elearning.trree. org/pluginfile.php/34691/mod_folder/content/0/3_2-CodeOnmedicalEthics. pdf?forcedownload $=1$

Conte, P., 2011, 'The role of religion during and after the civil war in Sierra Leone', Journal of the Study of Religion 24(1), 55-76.

Daly, J.L., 2012, Human resource management in the public sector: Policies and practices, M.E. Sharpe, New York.

De Lange, F., 2011, Restoring autonomy: Symmetry and asymmetry in care relationships, SUNScholar Research Repository, Stellenbosch University.

Dhai, A. \& Etheredge, H., 2011, 'Codes of health care ethics', in A. Dhai \& D. McQuoidMason (eds.), Bioethics, human rights and health Law: Principles and practice, pp. 16-34, Juta, Cape Town.

Dhai, A. \& McQuoid-Mason, D., 2011, Bioethics, human rights and health law: Principles and practice, Juta, Cape Town.

Diagnostic and Statistical Manual for Mental Disorders: DSM-IV-TR, 2000, American Psychiatric Association, Washington, DC.

Doran, D., 2005, 'Teamwork - nursing and the multidisciplinary team', in L.M. Hall (ed.), Quality work environments for nurse and patient safety, pp. 39-62, viewed 21 February 2013, from http://book.google.co.za

Dougherty, A.M., 2009, Psychological consultation and collaboration in school and community settings, Brooks/Cole, Cengage Learning, Belmont.

Dukor, M., 2010, Theistic humanism of African philosophy: The great debate on substance and method of philosophy, LAP Lambert Academic Publishing, Saarbrucken.

Eaton, J. \& Agomoh, A., 2008, 'Developing mental health services in Nigeria: The impact of a community-based mental health awareness programme', Social
Psychiatry Psychiatric Epidemiology 43(7), 552-558. http://dx.doi.org/10.1007/ s00127-008-0321-5

Ecoma, E.E., 1996, 'Binding the wounds: Presbyterians and the health of the nation', in O.O. Kalu (ed.), A century and a half of Presbyterian witness in Nigeria, 18461996, pp. 175-192, Ida-Ivory Press, Lagos.

Elger, B.S., 2009, 'Factors influencing attitudes towards medical confidentiality among Swiss physicians', Journal of Medical Ethics 35(8), 517-524. http://dx.doi. org/10.1136/jme.2009.029546

Ellis, J.R. \& Hartley, C.L., 2008, Nursing in today's world: Trends, issues, and management, 9th edn., Wolters Kluwer/Lippinport Williams \&Williams, Philadelphia.

Erde, E., Pomerantz, S.C., Saccocci, M., Kramer-Feeley V. \& Cavalieri T.A., 2006, 'Privacy and patient-clergy access: Perspectives on patients admitted to hospital', Journal of Medical Ethics 32(7), 398-402. http://dx.doi.org/10.1136/ jme.2005.012237

Eyer, R., 1991, 'Building mutual trust and respect within the chaplain/physician relationship', in L. VandeCreek \& L. Burton (eds.), The chaplain-physician relationship, pp. 19-31, The Haworth Press, New York.

Fallon, L.F. \& McConnell C.R., 2014, Human resource management in healthcare, Jones and Barlett Learning, Burlington.

Flannelly, K.J., Galek, K., Bucchino, J., Handzo, G. \& Tannenbaum, H., 2005, 'Department directors' perceptions of the roles and functions of hospital chaplains: A national survey', Hospital Topic 83(4), 19-27. http://dx.doi.org/10.3200/HTPS.83.4.19-28

Flannelly, K.J., Handzo, G. \& Weaver, A., 2003, 'A three-year study of chaplains' professional activities at Memorial Sloan-Ice Hering Cancer Center in New York professional activities at Memorial (8), 760-768. http://dx.doi.org/10.1002/pon.700
City', Psycho-Oncology 12(8)

Gerkin, C.V., 1997, An introduction to pastoral care, Abingdon Press, Nashville.

Hawkes, G., 1991, 'The relationship between theology and practice in South African pastoral theology', in M. Mpolo \& D. Nwachuku (eds.), Pastoral care and counseling in Africa today, n.p., Peter Lang, Frankfurt am Main.

Hill, P.C. \& Smith, G.R., 2010, 'Coming to terms with spirituality and religion in the workplace', in R.A. Giacalone \& C.L. Jurkiewicz (eds.), Handbook of workplace spirituality and organizational performance, 2nd edn., pp. 171-184, M.E. Sharpe, New York.

Hirsto, L. \& Tirri, K., 2009, 'Motivational approaches to the study of theology in relation to spirituality', Journal of Empirical Theology 22(1), 88-102. http:// dx.doi.org/10.1163/157092509X437233

Hunter, R.J., 1995, 'The therapeutic tradition of pastoral care and counseling', in P.D. Couture \& R.J. Hunter (eds.), Pastoral care and social conflict: Essays in honor of Charles Gerkin, pp. 17-31, Abingdon Press, Nashville.

Ibrahim, N.A. \& Odusanya, O., 2009, 'Knowledge of risk factors, beliefs and practices of female health care professionals towards breast cancer in a tertiary institution in Lagos, Nigeria', BMC Cancer 9, 76. http://dx.doi.org/10.1186/1471-2407-9-76 
Igonoza, A.O., 1994, 'Wholeness in African experience: Christian perspectives', in E.Y Lartey, D. Nwachukwu \& W.K. Kasonga (eds.), The church and healing: Echoes from Africa, vol. 2, pp. 124-137, Peter Lang, Frankfurt am Main.
from

Johnson, C.P., 2001, 'An Islamic understanding of health care: What can it teach us?', Accident and Emergency Nursing 9(1), 38-45. http://dx.doi.org/10.1054/ aaen.2000.0186

Koenig, H.G., King, D.E. \& Carson, V.B., 2012, Handbook of religion and health, Oxford University Press, New York.

Koopman, N., 2006, 'Curing or caring? Theological comments on healing', Religion and Theology 13(1), 38-53. http://dx.doi.org/10.1163/157430106778007716

Koopsen, C. \& Young, C., 2009, Integrative health: A holistic approach for health professionals, Jones and Barlett Publishers, Sudbury.

Kreindler, S.A., Dowd, D.A., Star, N.D \& Gottschalk, T., 2012, Silos and social identity: The social identity approach as a framework for understanding and overcoming division in health care, The Milbank Quarterly: An Interdisciplinary Journal of Population Health and Health Policy 90(20), 347-374.

Landman, C., 2009, Township spiritualities and counselling, Research Institute for Theology and Religion, Pretoria.

Landman, C., 2013, 'The (de)construction of religious identity in oral history research in South Africa, Studia Historiae Ecclesiasticae 39(1), 247-259.

Lee, R. \& Nash, H., 2009, Defining waste: What's the (re-)use?, viewed 03 March 2014, from http://www.tcetoday.com

Louw, D.J., 2008, Cura vitae: Illness and the healing of life, Lux Verbi, Wellington.

Mbiti, J.S., 1999, African religion and philosophy, Heinemann Educational Publishers, Oxford.

McCurdy, D.B \& Fitchett, G., 2011, 'Ethical issues in case study publication: 'Making our case(s)' ethically', J Health Care Chaplain 17(1/2), 55-74. http://dx.doi.org/10 $.1080 / 08854726.2011 .559855$

Metuh, E.I., 1999, God and man in African religion, SNAAP Press Ltd, Enugu.

Moodley, K., 2011, 'Respect for patient autonomy', in K. Moodley (ed.), Medical ethics, law and human rights: A South African perspective, pp. 41-55, Van Schaik, Pretoria.

Morgan, A., 2000, What is narrative therapy? An easy-to-read introduction, Dulwich Centre Publications, Adelaide.

National Center on Complementary and Alternative Medicine, 2011, viewed 04 March 2011, from http://nccam.nih.gov

National Planning Commission of South Africa, 2011, National health development plan 2030, viewed 03 June 2014, from http://www.npconline.co.za/medialib/ download/home/pd

Nigerian Federal Ministry of Health, 2005a, Draft health promotion policy for Nigeria 2005, viewed 21 February 2013, from http://www.fmh.gov.ng

Nigerian Federal Ministry of Health, 2005b, National policy on public private partnership for health in Nigeria (NPPPPHN), viewed 21 February 2013, from http://www.fmh.gov.ng

Nigerian Federal Ministry of Health, 2010, National strategic health development plan (NSHDP) 2010-2015, viewed 21 February 2013, from http://www.fmh.gov.ng

Orton, M.J., 2008, 'Transforming chaplaincy: The emergence of a health care pastoral care for a post-modern world', Journal of Health Care Chaplain 15(2), 114-131, viewed 06 September 2011, from http://www.tandfonline.com.ez.sun.ac.za
Osmer, R.R., 2008, Practical theology: An introduction, William B. Eerdmans, Grand Rapids.

Park, S.K., 2010, 'A postfoundationalist research paradigm of practical theology', HTS Teologiese Studies/Theological Studies 66(2), 6 pages. http://dx.doi.org/10.4102/ hts.v66i2.849

Piderman, K.M., Marek D.V., Jenkins S.M., Johnson M.E., Buryska J.F., Shanafelt T.D. et al., 2010, 'Predicting patients' expectations of hospital chaplains: A multisite survey', Mayo Clinic Proceedings 85(11), 1002-1010. http://dx.doi.org/10.4065/ mcp.2010.0168

Ramsay, N.J., 2004, 'A time of ferment and redefinition', in N.J. Ramsay (ed.), Pastoral care and counseling: Redefining the paradigms, pp. 1-44, Abingdon Press, Nashville.

Read, N., 2006, Sick and tired: Healing the illnesses doctors cannot cure, Phoenix, London.

Reese, D.A. \& Sontag, M., 2001, 'Successful interprofessional collaboration on the hospice team', Health Social Work 26(3), 167-195. http://dx.doi.org/10.1093/ hsw/26.3.167

Smeet, W., Gribnau, F. \& Van der Ven, J., 2011, 'Quality assurance and spiritual care', Journal of Empirical Theology 24, 80-121. http://dx.doi. org/10.1163/157092511X571187

Stuber, M.L \& Horn, B., 2012, 'Complementary, alternative, and integrative medicine', in M. Cobb, R. Rumbold, C.M. Pulchalski (eds.), Spirituality in health care, pp. 191-195, Oxford University Press, New York.

Swinton, J., 2003, 'A question of identity: What does it mean for chaplains to become health care professionals?', Scottish Journal of Health care Chaplaincy 6(2), 2-8.

Tovino, S., 2005, 'Hospital chaplaincy under the HIPAA privacy rule: Health care or 'just visiting the sick'?', Indiana Health Law Review 2(49), 51-93, viewed 01 September 2011, from http://www.heinonline.org

VandeCreek, L.D., 2010, 'Defining and advocating for spiritual care in the hospital', Journal of Pastoral Care Counsel 64(2), 1-10.

VandeCreek, L.D. \& Burton, L., 2001, 'Professional chaplaincy: Its role and importance in health care', Journal of Pastoral Care 55(1), 81-97.

Van Huyssteen, J.W., 1999, The shaping of rationality: Toward interdisciplinarity in theology and science, William Eerdmans, Grand Rapids.

Wikipedia, n.d., Health human resources, viewed 03 May 2014, from http:// en.wikipedia.org/wiki/Health_human_resources

Wittenberg-Lyles, E., Oliver, D.P., Demiris, G., Baldwin, P. \& Regehr, K., 2008, 'Communication dynamics in hospice teams: Understanding the role of the chaplain in interdisciplinary team collaboration', Journal of Palliative Medicine 11(12), 1330-1335. http://dx.doi.org/10.1089/jpm.2008.0165

World Health Organization (WHO) 1998, Department of mental health, social change cluster, 1998, WHOQOL and spirituality, religiousness and personal beliefs, viewed 15 January 2013, from http://whqlibdoc.who.int/hq/1998/who_MSA_ MHP_98.2_eng.pdf

World Health Organization (WHO), 2000, World health report: How well do health systems perform?, viewed 23 May 2014, from http://www.who.int/whr/2000/ en/whr00_ch2_en.pdf

World Health Organization (WHO), 2010, Key components of a well-functioning health system, viewed 16 August 2012, from http://who.int/healthsystem/EN_ HSSkeycomponents.pdf 